\title{
O Teatro Fórum como dispositivo de discussão da violência contra a mulher
}

\author{
The Forum Theatre as a tool for discussion \\ about violence against women
}

\author{
Érika Cecília Soares OLIVEIRA \\ Maria de Fátima ARAÚJO'
}

\section{Resumo}

Este artigo apresenta resultados de uma pesquisa que utilizou o Teatro do(a) Oprimido(a), na modalidade do Teatro Fórum, para promover discussões e reflexões sobre a violência contra a mulher, através de um esquete sobre o tema apresentado para um grupo de catadoras(es) de material reciclável de duas cidades do interior paulista. No Teatro Fórum, os(as) espectadores(as) transformam-se em espect-atores/atrizes e, pela via da ação, ajudam a encontrar uma solução para o conflito encenado. Os resultados da pesquisa sugerem que o Teatro do(a) Oprimido(a) possa ser usado como uma importante ferramenta metodológica de pesquisa. No campo específico da Psicologia, esse dispositivo teatral aparece como um instrumento alternativo para trabalhar com pesquisas participativas que envolvem diversas temáticas e questões da coletividade e que produzem rupturas em práticas e discursos hegemônicos.

Palavras-chave: Identidade de gênero; Pesquisa participativa; Teatro do Oprimido; Violência contra a mulher.

\begin{abstract}
This article presents the results of a study that made use of the Theatre of the Oppressed, in its Forum Theatre form, to promote discussions and reflections on violence against women. This was achieved through a sketch about the theme shown to a group of recyclable material collectors from two towns in the interior of the State of São Paulo. In the Forum Theatre the spectators become actors/actresses and, through the activity, help to find a solution for the enacted conflict. The results of the study suggest that the Theatre of the Oppressed can be used as an important methodological procedure for research. In the field of Psychology specifically, this theatrical tool emerges as an alternative device in order to work with participative studies involving diverse themes and issues of a community, producing ruptures in hegemonic practices and discourses.
\end{abstract}

Keywords: Gender identity; Participative research; Theatre of the Oppressed; Violence against women

\section{$\boldsymbol{\nabla} \nabla \mathbf{v}$}

1 Universidade Estadual Paulista Júlio de Mesquita Filho, Faculdade de Ciências de Letras, Programa de Pós-Graduação em Psicologia. Campus de Assis, Av. Dom Antônio, 2100, 19806-900, Assis, SP, Brasil. Correspondência para/Correspondence to: E.C.S. OLIVEIRA. E-mail: <oliverik_br@yahoo.com.br>.

Artigo elaborado a partir da tese de E.C.S. OLIVEIRA, intitulada "Gênero, violência contra a mulher e Teatro do(a) Oprimido(a): construindo novas possibilidades de pesquisa e intervenção social". Universidade Estadual Paulista Júlio de Mesquita Filho, 2013.

Agradecimento: Aos(às) Catadores(as) de Material Reciclável que fizeram parte desta pesquisa e que nos abriram as portas das cooperativas e das associações.

Apoio: Fundação de Amparo à Pesquisa do Estado de São Paulo (Processo no 2010/08017-1). 
Este artigo apresenta um relato de experiência oriundo de uma pesquisa de doutorado em Psicologia cujo objetivo foi promover discussões sobre a Violência Contra a Mulher (VCM) por meio do Teatro do(a) Oprimido(a) (TO), como instrumento metodológico na modalidade de Teatro Fórum (TF). Criado por Augusto Boal, o método é muito utilizado, em todo o mundo, em trabalhos de intervenção social e política, com minorias oprimidas (Boal, 2005). Apesar disso, é ainda pouco discutido e explorado nas pesquisas acadêmicas brasileiras.

O Teatro do Oprimido surge no cenário brasileiro em plena ditadura militar e, através dessa Poética da Liberação (Boal 2005, 2009a, 2009b), anuncia um novo lugar para a plateia dentro do teatro brasileiro. Caracterizado como um teatro político, que se preocupa com os problemas da realidade brasileira, o TO tem como pretensão restabelecer a voz dos(as) oprimidos(as), provocando um ato de transgressão no ritual teatral convencional. Fazendo afirmações polêmicas nas quais dizia que todos(as) poderiam fazer teatro, até mesmo atores e atrizes, o teatrólogo pretendia mostrar que todos os seres humanos têm as mesmas capacidades e estão aptos, portanto, a executarem tarefas idênticas, desde que as condições para isso thes sejam oferecidas. Esse ponto de vista rompia com o status quo reinante no meio teatral e colocava as formas de se fazer teatro nas mãos de todos(as). Boal levou essa nova forma de pensar o teatro para países do mundo inteiro, pondo no palco as mais diferenciadas pessoas: camponeses(as), operários(as), trabalhadores(as), estudantes etc.

No caso específico do TF, os(as) espectadores(as) são convidados(as) a entrar em cena e, teatralmente, pela ação, encontrar estratégias para o conflito apresentado. Essa profanação da cena (lugar, a priori, habitado apenas por atores/atrizes) dá ao teatro uma dimensão democrática de aprendizado coletivo. A fim de realizar a mediação entre palco e plateia, Boal (2005) criou o(a) curinga, cuja denominação faz referência à carta do baralho, que, por sua versatilidade, pode ocupar várias funções no jogo. O(a) curinga do TO, além de fazer a mediação, é um(a) multiplicador(a) da técnica, coor- dena a criação do texto a ser apresentado, agrega e organiza as ideias do grupo, dirige, faz a marcação de cena etc. (Silva, 2009).

Para a pesquisa de doutorado, construiu-se um esquete sobre o tema, apresentado em cinco sessões de TF para diferentes grupos de mulheres e homens de três cidades do interior do oeste paulista. Esse relato de experiência pretende contemplar dois desses grupos: uma Cooperativa de Catadores(as) de Material Reciclável e uma Associação de Catadores(as) de Material Reciclável.

Era também objetivo da pesquisa avaliar o potencial do TO como ferramenta a ser incluída no campo das metodologias de pesquisas participativas, por possibilitar uma construção coletiva entre pesquisador(a) e pesquisados(as), na qual a voz de todos os sujeitos fosse norteadora das opressões e das ações que deveriam ser discutidas e, quiçá, resolvidas. Para o campo específico da Psicologia, o TO aparece com um dispositivo emancipatório e alternativo que se propõe a trabalhar de modo amplo com as várias questões da coletividade, produzindo diversas rupturas nos discursos e práticas hegemônicas, dentre eles aqueles do próprio campo dos saberes e fazeres da área da Psicologia. Pode, portanto, constituir-se como um poderoso instrumento de intervenção social e análise crítica da realidade.

O referencial teórico que orientou o desenvolvimento da pesquisa e a análise das ações e intervenções realizadas no TF foi a perspectiva feminista de gênero (Butler 2003, 2007, 2011; Fraser, 2006, 2007; Lauretis, 1994; Rubin, 2003; Scott, 1995), que reúne um amplo quadro conceitual, desenvolvido por diferentes teóricas feministas, para pensar as questões de gênero e violência, identidade e subjetividade e outras dimensões da vida social e cultural.

A produção da subjetividade é compreendida neste trabalho como a junção da história pessoal do sujeito com situações, discursos e identidades coletivas. Dentro desse contexto, gênero e identidade de gênero agem como princípios estruturantes que marcam tanto a vida social como a subjetividade das pessoas, juntamente com outros eixos de relação de poder e diferenciação, tais como 
etnia, classe social, sexualidade, religião, nacionalidade, dentre outros. Discursos, categorias e tecnologias sociais participam da produção e da reprodução dos sujeitos "marcados por gênero", que, por sua vez, constroem a si mesmos através deles. Junto com Lauretis (1994), poderíamos dizer que o sistema sexo-gênero é tanto uma construção sociocultural quanto um aparelho semiótico.

Nossos padrões culturais promovem uma inteligibilidade de gênero (Butler, 2003, 2007, 2011) e participam da construção das representações e autorrepresentações dos sujeitos marcados por ele. Esses sujeitos, por sua vez, assumem, ao longo da vida e em diferentes momentos, várias posições fundadas no gênero. Como discursos, essas representações têm força tanto material como social, não se resumindo a um simples apanhado de ideias (Lauretis, 1994; Moore, 2000). Para Moore (2000), é porque existem discursos concorrentes e contraditórios que algumas pessoas assumem determinadas posições de sujeito e não outras, ou, dito de outro modo, uma mulher assume certa posição diante do que é ser feminina e não outra, o mesmo valendo para o homem.

Outro conceito que orientará esta análise é a concepção de justiça de gênero, desenvolvida por Fraser $(2006$, 2007). Para a autora, gênero é uma categoria bidimensional, que contém tanto uma face política e econômica quanto uma face discursivo-cultural. A primeira traz consigo o âmbito da redistribuição, e, a segunda, o âmbito do reconhecimento. Ambas devem ser levadas em consideração quando se quer discutir justiça e injustiça de gênero.

De acordo com Fraser $(2006,2007)$, em sua dimensão política e econômica, gênero teria afinidade com classe, e, em sua dimensão discursivo-cultural, ele teria mais afinidade com status. $\mathrm{Na}$ primeira dimensão, gênero apareceria como uma diferenciação semelhante à classe, enraizado na própria estrutura econômica da sociedade, sendo claramente visível no modo como se dá a organização de trabalho (trabalho "produtivo" pago para os homens, com melhores salários, em contraposição ao trabalho "reprodutivo" doméstico e não pago das mulheres, ou, quando empregadas, sempre com salários inferiores). A estrutura econô- mica, dessa forma, geraria formas específicas de injustiça distributiva baseadas no gênero. Já em sua dimensão de reconhecimento, o gênero apareceria como uma diferenciação de status enraizada na própria sociedade, codificando padrões culturais de interpretação e avaliação, que são centrais nessa ordem.

Para a autora, uma das principais características da injustiça de gênero é o androcentrismo, que valoriza tudo o que está relacionado ao universo masculino e, em igual medida, desvaloriza aquilo que é entendido como feminino. Esses padrões estão distribuídos em várias áreas do Direito, das políticas governamentais, nas práticas profissionais padronizadas, na cultura popular, bem como nas interações cotidianas, fazendo, assim, parte dos discursos culturais dominantes que influenciam a formação da identidade de gênero.

Diante do até agora exposto, pode-se pensar a violência surgindo dentro desses construtos que interpretam o que é ser mulher e o que é ser homem, atribuindo-Ihe papéis, expectativas e normas a serem seguidas. Como um fenômeno complexo, a violência articula relações de poder, dominação e submissão, geradas pelo sistema sexo/gênero.

\section{Método}

A pesquisa adota a abordagem qualitativa e busca articular os referenciais teoricometodológicos de gênero com o TO. O conceito de metodologia é utilizado neste trabalho de acordo com Minayo (2010), que o define como um conjunto de concepções teóricas e de técnicas que possibilitam a apreensão da realidade pesquisada e o desenvolvimento do potencial criativo do(a) pesquisador(a).

A proposta de trabalhar com diferentes teorias, métodos e técnicas, numa perspectiva multidisciplinar, insere-se no campo de estudos e pesquisas feministas de gênero (Narvaz \& Koller, 2006; Olesen, 2008) e permite apreender as questões de gênero que atravessam a experiência e a subjetividade das mulheres (e também dos homens) numa perspectiva crítica e política, levando-se em 
conta a diversidade, as diferenças, os aspectos ideológicos, epistemológicos e éticos envolvidos na escolha do paradigma de pesquisa (Olesen, 2008).

As apresentações para o grupo de catadoras(es) se deram no próprio local de trabalho: a Cooperativa e a Associação de Catadores(as). Duas sessões de TF foram realizadas com duração de aproximadamente uma hora cada, em respeito ao tempo proposto pela plateia, composta por aproximadamente 50 pessoas na cooperativa e 26 pessoas na associação, em sua maioria mulheres.

A participação na pesquisa foi espontânea e todos(as) os(as) participantes assinaram o termo de consentimento, conforme Resolução CNS196/ 96. O critério para a escolha dos grupos para a apresentação do esquete foi o de incluir pessoas que não tinham acesso a esse tipo de produção artística. Para a produção do esquete, formou-se um grupo de alunos(as) de graduação, da própria universidade, interessados(as) no fazer teatral. Através de oficinas com jogos e exercícios dramáticos baseados no TO, o grupo foi capacitado e criou-se o esquete intitulado "Segura meu coração", para ser apresentado por meio do fórum. No caso dessas duas apresentações, a curingagem (isto é, a mediação entre plateia e palco) foi feita pela própria protagonista; somente nas apresentações posteriores, a própria pesquisadora exerceu tal função. Depois de realizado o fórum, optou-se por abrir um espaço para conversar com a plateia, por se supor que muitas pessoas que não desejaram intervir na cena poderiam dar sua opinião nesse segundo momento. Optou-se por chamar esse momento posterior às apresentações de "roda de conversa". Nesse relato, analisa-se o resultado de algumas falas que foram consideradas exemplares para a discussão aqui apresentada. Essas falas foram retiradas tanto da contribuição dada pelas espect-atrizes que entraram em cena como também das opiniões emitidas na roda de conversa.

A elaboração do roteiro seguiu as indicações de Boal (2005), para a construção de uma dramaturgia de Teatro Fórum, priorizando, portanto, a existência de um conflito que deveria ser solucionado pela plateia. A pesquisadora optou por 260 fazer uma bricolagem de textos e de frases de livros, e escolheu como história norteadora do livro "O dia dos prodígios", da escritora portuguesa Jorge (1990), além de frases retiradas da peça de teatro "Mateus e Mateusa", do dramaturgo Qorpo Santo (Campos, 1980), do conto "Agda", da escritora brasileira Hilst (2002) e de trechos produzidos pela própria pesquisadora, o que gerou um texto que contemplava a discussão sobre a violência doméstica. Além disso, o grupo procurou incorporar, entre as cenas apresentadas, trechos de músicas, dentre elas, a do CD de Tom Zé, "Estudando o Pagode: na opereta Segregamulher e Amor", na qual o cantor e com-positor faz um estudo a respeito das várias opressões que a mulher vem sofrendo ao longo da história. Uma vez escolhido o roteiro, as atrizes prepararam-se para encená-lo.

O registro dos dados foi feito por gravação e filmagens das falas, por imagens dos(as) participantes e, também, por observações registradas pela pesquisadora no diário de campo.

A pesquisa cumpriu todos os princípios éticos estabelecidos pelo Comitê de Ética, atendendo as legislações específicas do País no qual ela foi realizada (Registro no CEP no 016/2010/Processo $n^{\circ}$ 1733/2010).

\section{Resultados e Discussão}

As paradas para que a plateia pudesse entrar em cena foram realizadas pela própria protagonista e se deram em momentos cujo impasse chegava ao ápice. Ao longo do esquete, que teve duração média de 10 minutos, foram escolhidos pelo menos três momentos cruciais para se paralisar a cena e pedir auxílio à plateia. Será realizada a descrição de cada um desses três momentos para, posteriormente, elencarem-se os temas mais frequentes como formas de resolução do conflito. Os personagens, retiradas e adaptadas do livro de Lídia Jorge, "O dia dos prodígios", chamavam-se Branca e Zé Pássaro Volante. O enredo conta a história de Branca, que borda a figura de um dragão numa colcha do tamanho da casa que seu pai havia Ihe deixado Seu trabalho doméstico e, consequentemente, sua obediência ao marido são mensurados por meio da execução dessa tarefa. Caso as escamas do dra- 
gão crescessem, o marido entenderia que a esposa havia ficado com o espírito para além dos muros da casa e isso implicaria em castigá-la. Nas palavras de Branca:

Porque se alguma coisa faltasse fazer, e as escamas do dragão crescessem. Ah, dedinhos! Eu estaria esquecendo dos meus deveres, e forçoso seria fazer-me lembrar. Cinco dedos estampados na pele. Não era pra doer. Era mais a marca e a lembrança.

A primeira cena narra a chegada do marido em casa e seu desejo de fazer com a esposa "aquilo que um homem e uma mulher fazem desde que o mundo é mundo!". Ao perceber que Branca se esquiva de fazer sexo sem vontade, o marido diz para a plateia que gostaria de ter uma mulher que, apesar de ser maltratada, ainda continuasse a dizer o quanto gostava dele.

Na segunda parada, a protagonista manifesta o desejo de sair, um dia, daquela situação:

\section{Eu espero acordar um dia sem sentir o peso do corpo, nem dos ossos, nem das miudezas do ventre. Estar em casa e pensar. Vou abrir a janela. E levantar-me para abrir a janela sem antes pesar quantas arrobas tem o meu assento sobre a cadeira onde estou sentada. Pensar. Vou chamar o Francisquinho. E não precisar de cortar as coleiras que me amar- ram a língua pra chamar por meu filho. Isso eu queria! Hei de ir-me embora um dia!}

Num terceiro momento, a cena é paralisada quando o antagonista faz menção ao modo como faria sexo forçado com Branca, podendo ser visualizado nessa passagem:

Zé Pássaro: - Já sei Branca, tive uma ideia! Vamos brincar assim: você é o meu corpo e eu sou teu corpo e eu quero comer o corpo da minha amada./ Branca: - Você promete que vai me amar? Zé Pássaro: - Prometo!/ Branca: - Você promete que vai ser mais carinhoso? Zé Pássaro: - Prometo! Zé Pássaro: - Eu pegaria ela e estraçalharia sua boca com meus beijos. Branca: - Eu morreria de medo, mas beijaria ele. Zé Pássaro: - Eu apertaria a carne dela até ela gemer. Branca:
- Eu me encolheria toda. Zé Pássaro: - Eu cavalgaria nela a noite toda. Branca: - Eu levaria ele pra todos os lugares. Zé Pássaro: Cansado, eu gozaria em todos os buracos do corpo dela. Branca: - Cansada, eu dormiria.

Esses são, portanto, os momentos mais cruciais para a intervenção da plateia. Uma vez encenados, a protagonista partia em busca de ajuda, procurando algum(a) espect-ator/atriz que pudesse vir com alguma tentativa de solução para o problema apresentado. Abaixo colocaremos as saídas sugeridas, lembrando que os nomes dos(as) espect-atores/atrizes bem como os lugares mencionados são fictícios. São nomes de personagens retirados de livros como "O dia dos prodígios", de Lídia Jorge, e "Kadosh", do qual foi retirado o conto "Agda", de Hilda Hilst.

\section{As duas faces da justiça de gênero}

Como o esquete convidava a plateia a pensar em alternativas concretas para a resolução da violência conjugal, pudemos notar que várias das tentativas de solução dadas pelas espect-atrizes tanto apontavam para sua crença no sistema judiciário como também refletiam a contribuição dos "discursos concorrentes e conflitantes" na formulação de um pensamento que trazia como informação que mulheres e homens têm direitos iguais, chegando até mesmo à ideia, por parte de algumas, de que a violência contra a mulher é coisa do passado. Associada a isso, também concorria como possibilidade de resolução do conflito a ideia de que a violência sofrida dentro de casa deveria ser revidada com mais violência.

A longa tradição institucional, cultural e discursiva que legitimou a VCM como algo tolerável em nossa sociedade durou até bem pouco tempo. Mesmo hoje, cinco anos após a promulgação da Lei Maria da Penha (Lei $n^{\circ} 11.340 / 2006$ ) pode-se acompanhar pelos noticiários casos em que esse tipo de violência é considerado como um problema de família a ser resolvido dentro da esfera privada, o que deixa, desse modo, a mulher em situação de 
violência vulnerável para sofrer mais violência, que, às vezes, resulta em sua própria morte.

Na análise da participação das espect-atrizes, toma-se como ponto de partida a contribuição de Fraser $(2006,2007)$, por meio de seu conceito de "justiça de gênero", que envolve duas dimensões: a distribuição (mudança na estrutura econômica) e o reconhecimento (mudança da cultura). Para ela, é inviável pensar numa dimensão sem falar da outra. Levar em conta as duas permitirá que se pense em como é construída no imaginário e nas práticas cotidianas das mulheres a possibilidade de encontrar alternativas que as defendam das violências sofridas, sobretudo aquelas que acontecem dentro de suas próprias casas. Pensemos na esfera do reconhecimento: quando mencionamos a criação de leis que dão às mulheres possibilidades de proteção, estamos falando de uma esfera que thes confere aquilo que Fraser $(2006,2007)$ chama de "paridade de participação", isto é, o direito de ser defendida e representada/tratada como um sujeito de direitos. A paridade teria, segundo ela, duas condições: uma objetiva, que exclui formas e níveis de desigualdade material e dependência econômica, e outra, intersubjetiva, que exclui normas institucionalizadas que sistematicamente depreciam categorias de pessoas e as características associadas a elas. No "modelo de status" mencionado por Fraser (2007), os sujeitos deverão ser parceiros integrais na interação social, participando como um igual na vida social, o que implicaria reconhecimento recíproco e igualdade de status.

No Brasil, até bem pouco tempo atrás, a VCM sequer constituía uma figura jurídica, definida pela lei criminal, dependendo, assim, das interpretações que os(as) operadores(as) do direito davam à queixa trazida pela mulher em situação de violência. Com a promulgação da Lei Maria da Penha, em 2006, essa situação começou a mudar, mas ainda estamos longe de um acesso igualitário à justiça, proteção integral à mulher e garantia dos seus direitos (Pougy, 2010). Embora garantidos pela lei, na prática, o acesso a tais direitos nem sempre funcionam, o que, provavelmente, contribui para o desamparo de muitas mulheres. Isso aparece em 262 algumas saídas sugeridas por nossas participantes, dentre elas, a fuga do lar, em que a mulher deixa muitas vezes os móveis, a casa e o filho, se necessário. Outras acreditam que esse tipo de situação deva ser resolvida dentro do espaço privado, por ser a mulher a única responsável para o término da violência que é cometida contra ela mesma.

Assim, diante do antagonista que diz para Branca que se ela se separasse dele não levaria nada, a espect-atriz Jesuína Palha diz: "Eu esperaria ele viajar, pegaria as coisas e iria para a casa da minha mãe ou de um parente com o Francisquinho [filho do casal]". É interessante notar a trajetória de possibilidades sugeridas por essa espect-atriz, que inicia com um "põe veneno na comida dele", ao lado de outra espect-atriz, Carminha, que também diz "dá um tiro nele", passando pela possibilidade de abandonar a casa com tudo. Apenas como última opção, vê-se na justiça um modo de resolver o impasse: isso acontece quando ela está em cena diante do opressor, que, nesse ponto, a ameaça de morte, caso ela o abandone. Diz ela: "cê acha que vai dar tempo? A justiça tem pra tudo! Até pra morte!".

Outra espect-atriz que também demonstra oscilações em sua crença no sistema judiciário é Agda, que, num primeiro momento, orienta Branca a deixar o antagonista, dizendo-lhe que deseja sua independência e a separação, mas que, na roda de conversa, diz:

Todas essas alternativas, se ele é um homem violento mesmo, não ia adiantar nada. Ela sozinha [a protagonista], ela procurasse ajuda, num centro de ajuda, fosse na delegacia, depusesse contra ele, querendo ou não a casa não é dele, mas é dos dois, o filho é dele, mas é dos dois, acho que o juiz faria ele ficar longe da mulher.

Mais adiante, ela menciona a experiência que teve com o ex-marido:

Eu tive que mentir pra ele que eu tava indo pra casa da minha mãe, que lá tinha mais oportunidade, que depois ele iria, porque naquela época a gente vivia como cão e gato, ia pra delegacia, fazia boletim de ocorrência, não acontecia nada com ele, ...eu mesma tava desacreditada, inda mais 
ele era conhecido, colega dos 'homens' ...eu menti pra ele, saí fugida e quando ele chegou lá, meus irmãos caçaram ele de cacete e falaram "some, não volta mais aqui".

Algumas espect-atrizes acabam concordando com Agda sobre a solução encontrada pelos irmãos dela, ou seja, que a violência contra o ex-marido poderia ser "exemplar" e que ele certamente deve ter aprendido algo com isso, não a procurando mais. Ainda a fala dela: "Tanto aprendeu que mora ainda em Vilamaninhos, faz 13 anos isso... e nunca mais".

Desacreditada do modo como a justiça encaminhava suas queixas e verificando que a alternativa de "dar o cacete" no ex-marido resolveria seu problema, essa espect-atriz nos fala de uma vivência que reforça o quanto as mulheres ficavam vulneráveis caso precisassem de uma proteção legal, tendo que apelar para os recursos extrajudiciais disponíveis. O pagamento de cestas básicas como penas alternativas usadas pelos Juizados Especiais Criminais (JECRIM) colocou em descrédito a viabilidade de uma justiça que defendesse a mulher e que levasse a sério suas reivindicações por proteção. A negação de direitos legais plenos, de proteção igualitária e de mecanismos inibitórios que combatessem a violência inscreveu, até o surgimento da Lei Maria da Penha, as mulheres como sujeitos inferiores ou desviantes, o que contribuiu para mantê-las em posição de desvantagem. Segundo Fraser (2006), o combate ao androcentrismo e ao sexismo exige uma mudança dos valores culturais - bem como de suas expressões legais e práticas, que negam respeito às mulheres -, revalorizando um gênero até então desprezado pelos discursos e pelas instituições.

Se, neste país, ficamos durante anos atolados(as) num imaginário que culpabilizava a mulher pela violência que sofria dentro de casa, e que autorizava o homem a "corrigir seus excessos", podemos dizer que é, sobretudo, a partir do advento da Lei Maria da Penha que se começa a criar um novo modo de pensar e também de agir frente à VCM, pois não há discurso sem prática ou vice-versa.

Com a nova lei, a mulher ganha um novo status dentro da sociedade, pois a ela é conferido o direito de não sofrer nenhum tipo de violência, o que lhe dá maior legitimidade junto às suas reivindicações de direitos mais igualitários. Ao prever um conjunto de políticas públicas e mecanismos de prevenção e repressão da violência, a lei permite que as mulheres deixem de ser tratadas como inferiores, excluídas, completamente "o outro" ou, simplesmente, invisíveis (Fraser, 2007).

Se concordarmos com Harvey (1989), que as representações das relações como complementares ou hierárquicas se referem também a noções locais de poder e autoridade, podemos pensar que é através das experiências culturais e sociais que se permitirá o reposicionamento das mulheres como sujeito de direitos.

Para exemplificar essa fala, trouxeram-se as intervenções de nossas espect-atrizes. A intervenção de Maria Rebôla acontece justamente quando o antagonista tenta reforçar a subordinação de Branca, utilizando-se, para tanto, da citação de um trecho bíblico. Com a bíblia na mão, a espect-atriz diz que vai mostrar-lhe que, no livro sagrado, a mulher e o homem se tornarão uma só carne. Em seguida, ela reivindica seus direitos: "Assim como você quer o respeito, eu também quero! Assim como você quer ser amado, eu também quero!" Maria Rebôla termina sua intervenção sendo muito aplaudida por uma plateia composta, em sua maioria, por mulheres. Carminha Rosa, outra espect-atriz, orienta Branca para dizer ao agressor que a mulher não nasceu para ser maltratada e que tem seus direitos. Matilde, em cena, afirmando ser uma mulher de opinião, avisa Zé Pássaro que pretende abandoná-lo, pois não vai aguentar sofrer nenhum tipo de violência, que vai embora, não importa o que ele faça contra ela, pois ninguém precisa desse tipo de vivência, ao que é muito aplaudida pela plateia. Roxana, por sua vez, tenta negociar com o antagonista, lembrando-lhe de que tem os mesmos direitos que ele: "Mulher também é ser humano, tem sentimentos. Tudo o que você quer eu também quero". Para provar seu ponto de vista, propõe: "Vamos trocar então? Aguentei teu filho nove meses na barriga, pari, cê vai parir?" e, mais adiante: "Se você quer, eu também quero, então vamos ter independência!". 
É importante compreender o posicionamento dessas mulheres como fruto de uma política de reconhecimento, abarcada por uma concepção igualitária de acesso à justiça para elas, pois, como Fraser (2007), entendemos que o não reconhecimento do status está diretamente ligado a relações sociais desiguais, tratando-se de uma questão de impedimentos, externamente manifestados e publicamente verificáveis.

\section{Rupturas nos discursos dominantes: a luta das catadoras por igualdade e pelo enfrentamento da violência}

Junto a esse novo posicionamento do Estado diante das demandas que procuram criminalizar a violência, ao mesmo tempo em que formula medidas mais eficazes de proteção e de prevenção, pode-se notar o nascimento de um discurso que coloca a mulher como alguém que deve estar em condições de igualdade. Dito de outro modo, isso implica no reconhecimento de um discurso que, ao que tudo indica, está concorrendo com aqueles dominantes que dizem ser a mulher inferior ao homem, devendo a ele ficar subordinada.

Essa opção contraditória na linguagem da diferença de gênero, ao que parece, permite, em alguma medida, que as mulheres consigam adotar posições de sujeito que auxiliem no enfrentamento da violência que sofrem em seu cotidiano e na visão de que é possível pensar em sua condição de um modo mais autônomo e independente, o que é reforçado, evidentemente, pela possibilidade de acesso que elas têm a um trabalho remunerado. É claro que um discurso concorrente sem uma prática que permita a vivência como sujeito de direitos garantidos pelo Estado, em esferas cotidianas, não é suficiente para que esse posicionamento possa acontecer. Deve-se reforçar que, além de um trabalho remunerado, a judicialização continua sendo um projeto essencial, já que universaliza o acesso à justiça de camadas alienadas dos direitos humanos, como nos adverte Pougy (2010).

Para ilustrar esse ponto de vista, apresenta-se a intervenção de Engrácia, que entrou na cena çado com Branca. Diz ela: "De jeito nenhum! Eu não iria deixar!". Quando ela diz ao Zé Pássaro que pretende deixá-lo e ele tenta dificultar sua decisão, dizendo-Ihe que ela não tem trabalho algum, portanto não terá o que comer, Engrácia retruca, dizendo: "Eu ia trabalhar". Ainda tentando dificultar, o antagonista lembra que a vila em que eles moram é minúscula, desacreditando-a da possibilidade de arrumar algum trabalho. Engrácia não se dá por vencida e continua: "Tem trabalho! Tem trabalho, a gente arruma, não tem só o bordado" e, ainda, quando o antagonista tenta fechar o cerco, dizendo que conhece toda a cidade, que vai contar para todo mundo que ela está louca, ameaçando-a de morte, ela finaliza: "Mas eu tenho certeza: de um lado ou de outro eu ia sair! Se você tem o seu lado eu também tenho o meu". Todo mundo aplaude a solução dada por Engrácia.

Na cooperativa, Engrácia é representante das várias catadoras que estavam ali no momento da apresentação. Ainda pensando na dimensão da distribuição como instância promotora da igualdade entre os pares, podemos aqui nos debruçar um pouco sobre a história dos(as) catadores(as) de material reciclável e seu acesso na sociedade como cidadãos(ãs) a partir do surgimento das cooperativas e das associações. Segundo Carvalho (2008), antes de existir a organização na forma de uma cooperativa, os(as) cooperados(as) provinham das mais diversas profissões: catadores(as) de rua, trabalhadores(as) desempregados(as) e aposentados(as) à procura de trabalho e de uma renda para auxiliar nas despesas do dia a dia. Uma característica comum a todos(as) era a luta individualizada pela sobrevivência, que Ihes retirava a crença em suas próprias potencialidades como sujeitos capazes de fazer um trabalho mais autônomo. Com a gradativa descoberta de que a autonomia caminhava em conjunto com a detenção dos meios de produção, os(as) catadores(as) associados(as) à cooperativa passam a ganhar mais confiança no próprio trabalho e a ter mais visibilidade junto à população. Paralelamente a isso, verificou-se que sua participação política parecia inevitável, pois o tipo de trabalho realizado por eles(as) pedia uma maior implicação com aquilo que estava acontecendo na sociedade. 
É interessante notar o caminho trilhado por eles(as), que vai do anonimato como cidadãos(ãs) explorados(as) por um sistema que os(as) coloca completamente à margem das decisões sociais até o momento em que, na cooperativa, juntam seus esforços para entender não apenas o funcionamento das etapas do trabalho com o material reciclável propriamente dito como também as decisões de caráter administrativo e político, pautadas em princípios de gestão solidária e democrática.

Entretanto, os(as) cooperados(as), pelo fato de serem cooperados(as) e não trabalhadores(as) com contratos regidos pela Consolidação das Leis do Trabalho (CLT), vivem em situação de vulnerabilidade social, já que muitos de seus direitos não são previstos pela Constituição Federal. Para a autora, gerar o próprio trabalho, bem como a renda advinda dele pela via da cooperativa popular, é uma alternativa importante para aqueles(as) que, de outro modo, teriam que ir em busca da sobrevivência de forma solitária, por meio de trabalhos em sua maioria precários. No entanto, como não são empregados(as), a maioria dos seus direitos sociais não é garantida.

O espaço da cooperativa permite relações mais igualitárias entre os(as) cooperados(as), afinal todos(as) são sócios(as); ao mesmo tempo, as próprias regras que regem o mundo do trabalho dentro de uma sociedade capitalista os(as) colocam novamente num campo de exclusão, que vai sendo reajustado à medida que eles(as) criam brechas e fissuras ao tentar negociar com outras instâncias para a obtenção de seus direitos. Pensar no papel da mulher que trabalha nesse espaço é uma tarefa complexa, já que constatamos que ela exercita sua cidadania nesse lugar na mesma medida em que não tem seus direitos como trabalhadora garantidos pelo Estado. Segundo Carvalho (2008), a atividade de catador(a) foi incluída na Classificação Brasileira de Ocupações recentemente.

De acordo com Harvey (1989), as mulheres não estão subordinadas em todos os níveis, isto é, em determinados lugares elas podem ter posições mais fortes e participativas, o que cria, dentro dos próprios eixos de relações de poder, a possibilidade de participarem como parceiras em iguais condições.
No espaço da cooperativa, elas mantêm relações não hierárquicas, com o mesmo poder de voz e decisão que os homens, o que indica a existência da multiplicidade de ações e discursos que estão disponíveis para elas. Talvez por isso, ainda que na plateia existissem homens, apenas as mulheres fizeram intervenções. Os homens permaneceram sentados no fundo, o que talvez tenha levado a protagonista a pedir ajuda diretamente às mulheres. No entanto, ouviram-se murmúrios de espect-atrizes que diziam para os homens, a fim de os estimular, que eles também poderiam entrar em cena. Entretanto, a única reação masculina se deu quando a protagonista estava no meio deles(as) e os convidou para entrarem em cena, e um homem disse que, se entrasse, iria dar porrada em todo mundo. Talvez isso se deva ao caráter provocativo do esquete: músicas cujas letras denunciavam as várias violências sofridas pelas mulheres ao longo da história, o modo muito direto de abordar a violência sofrida pela protagonista e também o fato de que, pelo menos até aquele momento, o antagonista ter sido mostrado apenas como o opressor (tal como Boal orienta a fazer). Além disso, o fato de que em cena só havia mulheres (tanto as atrizes como as espect-atrizes) deve ter contribuído para esse tipo de reação, que, se analisada por si só, mostra que, para aquele espect-ator, só seria possível discutir a questão através de um ato violento. Pode-se até mesmo afirmar que estávamos dentro de uma "panela de pressão", pois, uma vez terminados a apresentação e o fórum, várias mulheres procuraram a protagonista, dizendo que haviam passado pela mesma situação que ela. Na roda de conversa, algumas relataram que haviam sofrido a mesma violência em seus casamentos e que haviam fugido, correndo risco de morte.

Se a lógica da desvantagem econômica das mulheres Ihes retira a participação igualitária na formação da cultura (Fraser, 2006), pode-se notar que isso passa a não funcionar na medida em que o trabalho dos(as) cooperados(as) é realizado de modo coletivo, com todos(as) participando em igual medida dos lucros obtidos pelo trabalho desenvolvido, o que permite que o "círculo vicioso da subordinação cultural e econômica" não se mantenha e fazendo, por sua vez, com que as normas 
culturais sexistas e androcêntricas possam ser questionadas no ambiente de trabalho. Desse modo, os autores deste trabalho concordam com Moore (2000), que diz que as categorias "mulher" e "homem" têm suas representações e autorrepresentações em suas práticas cotidianas. Pode-se dizer que, pelo menos diante do que foi observado, a prática das catadoras tem sido de resistência às categorias culturais dominantes.

Pode-se exemplificar essa afirmação relatando que, antes da apresentação do esquete, fomos convidadas por uma das técnicas do projeto de extensão desenvolvido pela Universidade, que faz a mediação com a associação, para realizarmos duas oficinas de TO com as catadoras. A demanda das catadoras era por algum auxílio na elaboração de uma pequena cena de teatro que queriam apresentar durante o I Encontro das Mulheres Catadoras do Oeste Paulista. A temática que elas queriam discutir estava diretamente relacionada com a presente pesquisa: o dia na vida de uma catadora, isto é, os transportes que tinha que utilizar até chegar ao local de trabalho; o cotidiano dentro da associação e, por fim, após um árduo dia de labuta, como era chegar em casa e ter um marido que não dividia as tarefas domésticas. O mais curioso e, ao mesmo tempo, gratificante é que elas já tinham o esquete completamente montado em suas cabeças, pois o estavam elaborando através de trocas de ideias durante o serviço. O auxílio, portanto, ficou mais restrito a dar uma ou outra dica sobre a sequência da apresentação, já que a construção já estava bastante avançada. É interessante notar a valoração dada por elas às duas oficinas, que foram realizadas durante seu período de trabalho e implicaram, portanto, na sua interrupção e na suspensão da produção por algumas horas. Nós já sabíamos que elas procuram interromper o menos possível suas atividades - já que isso implica a diminuição de sua produção -, o que demonstra o quanto aquela discussão tinha caráter relevante para elas.

Foi possível, então, observar como essas mulheres conseguem criar rupturas, através de suas problematizações, na hegemonia dos discursos androcêntricos. Ao tentarem romper, por intermé- culturalmente, que relegam a mulher à jornada dupla de trabalho, naturalizando essa prática, elas procuravam criar um novo olhar para os papéis de gênero, colocando em cheque os binarismos tão caros às reproduções estereotipadas do que é ser mulher ou homem. Sua atitude faz lembrar as palavras do cantoneiro ao se referir à Branca, em O dia dos prodígios: "Ninguém se liberta se não quiser libertar-se" (Jorge, 1990, p.105). Tais atitudes cooperam para que posturas de enfrentamento as auxiliem a lidar com os atravessamentos - sociais, jurídicos e discursivos -, que dificultam o caminho de igualdade entre mulheres e homens.

Encerra-se esta discussão citando Esperança Teresa, uma espect-atriz que, ao final das discussões, após a apresentação do nosso esquete, diz: "Então, vocês estavam falando ali o negócio do homem, da mulher, mas gente, hoje a lei mudou, hoje a lei é da mulher, não existe isso, ficar oprimido lá dentro, ... acabou!". Queremos, junto com Esperança Teresa, acreditar que "hoje a lei é da mulher" e que, a partir de agora, estamos caminhando para uma sociedade em que a justiça seja feita, em igual medida, tanto para mulheres como para homens.

\section{Referências}

Boal, A. (2005). Teatro do Oprimido e outras poéticas políticas. Rio de Janeiro: Civilização Brasileira.

Boal, A. (2009a). A estética do oprimido. Rio de Janeiro: Garamond.

Boal, A. (2009b). O teatro como arte marcial. Rio de Janeiro: Garamond.

Brasil. Casa Civil. (2012). Lei no 11.340, de 7 de agosto de 2006. Lei Maria da Penha. Brasília: Casa Civil.

Butler, J. (2003). Sujeitos do sexo/gênero/desejo. In J. Butler. Problemas de gênero: feminismo e subversão da identidade (pp.17-60). Rio de Janeiro: Civilização Brasileira.

Butler, J. (2007). El género en disputa: el feminism y la subversión de la identidad. Barcelona: Paidós Ibérica.

Butler, J. (2011). Bodies that matter: On the discursive limits of "sex". New York: Routledge.

Campos, J. J. L. (Corpo Santo). (1980). Mateus e Mateusa. In C. Guilhermino (Org.), Teatro completo (pp.87-101). Rio de Janeiro: Fundação Nacional de Arte. Recuperado em março 3, 2011, de http://www.dominio publico.gov.br/download/texto/bv000296.pdf 
Carvalho, A. M. R. (2008). Cooperativa de Materiais Recicláveis de Assis - COOCASSIS: espaço de trabalho e de sociabilidade e seus desdobramentos na consciência (Tese de doutorado não-publicada). Programa de Pós-Graduação em Psicologia, Universidade de São Paulo.

Fraser, N. (2006). Da redistribuição ao reconhecimento? Dilemas da justiça numa era "pós-socialista". Cadernos de Campo, 14/15, 231-239.

Fraser, N. (2007). Reconhecimento sem ética? Lua Nova, 70,101-138.

Harvey, P. (1989). Género, autoridad y competencia lingüística: participación política de la mujer em pueblos andinos. Documento de Trabajo 33(9) Recuperado en junio 11, 2011, disponíble en http:// www.iep.org.pe/textos/DDT/ddt33.pdf

Hilst, H. (2002). Kadosh. São Paulo: Editora Globo.

Jorge, L. (1990). O dia dos prodígios. Portugal: Publicações Europa-América.

Lauretis, T. (1994). A tecnologia do gênero. In H. B. Hollanda (Org.), Tendências e impasses: o feminismo como crítica da cultura (pp.206-242). Rio de Janeiro: Rocco.

Minayo, M. C. S. (Org.). (2010). O desafio do conhecimento: pesquisa qualitativa em saúde. São Paulo: Hucitec.
Moore, H. L. (2000). Fantasias de poder e fantasias de identidade: gênero, raça e violência. Cadernos Pagu, $14,13-44$

Narvaz, M. G., \& Koller, S. H. (2006). Metodologias feministas e estudos de gênero: articulando pesquisa, clínica e política. Psicologia em Estudo, 11(3), 647-654.

Olesen, V. L. (2008). Os feminismos e a pesquisa qualitativa neste novo milênio. In N. K. Denzin \& Y. S. Lincoln (Orgs.), O planejamento da pesquisa qualitativa: teorias e abordagens (pp.219-57). Porto Alegre: Artmed.

Pougy, L. G. (2010). Desafios políticos em tempos de Lei Maria da Penha. Revista Katállysis, 13(1), 76-85.

Rubin, G. (2003). El tráfico de mujeres: notas sobre la "economía política" del sexo. In M. Lamas. El género: la construcción cultural de la diferencia sexual. México: UNAM.

Silva, C. V. (2009). Curinga uma carta fora do baralho: a relação diretorlespectador nos processos e produtos de espetáculos fórum (Dissertação de mestrado não-publicada). Universidade Federal da Bahia, Salvador.

Scott, J. W. (1995). Gênero: uma categoria útil de análise histórica. Educação e Realidade, 20(2), 71-99.

Recebido em: 2/12/2012

Versão final em: 23/4/2012

Aprovado em: 14/5/2012 
